\title{
Are Mutations of the EGFR Gene Promising Predictive Markers for Anti-EGFR mAbs in Colorectal Carcinomas?
}

\author{
Dong-Guk Park \\ Department of Surgery, Dankook University School of Medicine, Cheonan, Korea
}

See Article on Page 127-132

Expression of epidermal growth factor receptor (EGFR) was found in $60-75 \%$ of colorectal carcinomas. Based on this, many studies have demonstrated the efficiency of monoclonal Abs (mAbs) in targeting the EGFR, such as cetuximab and panitumumab, in metastatic colorectal cancer (mCRC) patients. Addition of cetuximab to irinotecan-based chemotherapy significantly improved the response rate and the progression-free survival (PFS) when compared with Cetuximab $\mathrm{mAb}$ alone (22.9\% vs. $10.8 \%$ and 4.1 vs. 1.5 months, respectively) [1].

Van Cutsem et al. $[2,3]$ reported that in chemonaive mCRC patients, the addition of anti-EGFR to irinotecan-based chemotherapy led to an $8.2 \%$ increase in the objective response (46.8\% vs. 38.4\%), a 0.9 -month increase in the progression free survival (PFS) (8.9 vs. 8 months) and a 1.3-month increase in the overall survival (19.9 vs. 18.6 months). Initially, the use of anti-EGFR $\mathrm{mAbs}$ was restricted to $\mathrm{mCRC}$ patients with expression of EGFR that was detectable using immunohistochemistry. However, due to the lack of immunohistochemistry predictive value and the variable clinical response, more reliable predictive markers of the response to anti-EGFR mAbs are needed [4].

Two types of molecular predictive markers have been investigated. The first is somatic mutations in EGFR pathway effectors, such as RAS-RAF-MAPK and PI3K-Akt-PTEN. Amplification of EGFR and overexpression of EGFR ligands are associated with sensitivity to anti-EGFR mAbs, but the mutations of BRAF and PIK3A and the loss of PTEN expression are associated with resistance to anti-EGFR mAbs $[2,5]$. The second is germline polymorphisms of genes involved in the EGFR path-

Correspondence to: Dong-Guk Park, M.D.

Department of Surgery, Dankook University School of Medicine, San 16-5

Anseo-dong, Dongnam-gu, Cheonan 330-715, Korea

Tel: +82-41-550-3931, Fax: +82-41-565-6167

E-mail:dkpark@dankook.ac.kr

(C) 2011 The Korean Society of Coloproctology

This is an open-access article distributed under the terms of the Creative Commons Attribution NonCommercial License (http://creativecommons.org/licenses/by-nc/3.0) which permits unrestricted noncommercial use, distribution, and reproduction in any medium, provided the original work is properly cited. way [6]. Nonetheless, at the present time, mutation of KRAS is the only negative molecular marker to anti-EGFR mAbs treatment $[2,5]$. Recently, a somatic mutation of the EGFR kinase domain was initially reported in lung cancer and later in colorectal carcinomas. In lung cancer, mutations in the EGFR gene are associated with a high response rate to EGFR tyrosine kinase inhibitors and are prognostic for a favorable outcome.

In this paper, the authors reported the incidence of the EGFR mutation in colorectal carcinomas as $22.41 \%$. The incidence was higher than reports in Western countries, and the EGFR mutation was increased in earlier stages and in the absence of lymph node metastasis. Also exon 20 was the only mutation site, which is different from reports in Japan (mutations in exon 19 and 20). The EGFR mutation state may be an important determinant in the resistance to anti-EGFR mAbs treatment. To address this, larger studies are needed, and hopefully it will be another predictive marker for anti-EGFR mAbs therapy in mCRC [7].

\section{REFERENCES}

1. Cunningham D, Humblet Y, Siena S, Khayat D, Bleiberg H, Santoro A, et al. Cetuximab monotherapy and cetuximab plus irinotecan in irinotecan-refractory metastatic colorectal cancer. N Engl J Med 2004;351:337-45.

2. Van Cutsem E, Kohne CH, Hitre E, Zaluski J, Chang Chien CR, Makhson A, et al. Cetuximab and chemotherapy as initial treatment for metastatic colorectal cancer. N Engl J Med 2009;360: 1408-17.

3. Van Cutsem E, Peeters M, Siena S, Humblet Y, Hendlisz A, Neyns B, et al. Open-label phase III trial of panitumumab plus best supportive care compared with best supportive care alone in patients with chemotherapy-refractory metastatic colorectal cancer. J Clin Oncol 2007;25:1658-64.

4. Chung KY, Shia J, Kemeny NE, Shah M, Schwartz GK, Tse A, et al. Cetuximab shows activity in colorectal cancer patients with tumors that do not express the epidermal growth factor receptor by immunohistochemistry. J Clin Oncol 2005;23:1803-10.

5. Di Fiore F, Blanchard F, Charbonnier F, Le Pessot F, Lamy A, Galais MP, et al. Clinical relevance of KRAS mutation detection in meta- 


\section{Coloproctology Dong-Guk Park}

static colorectal cancer treated by Cetuximab plus chemotherapy. Br J Cancer 2007;96:1166-9.

6. Graziano F, Ruzzo A, Loupakis F, Canestrari E, Santini D, Catalano $\mathrm{V}$, et al. Pharmacogenetic profiling for cetuximab plus irinotecan therapy in patients with refractory advanced colorectal cancer.
J Clin Oncol 2008;26:1427-34.

7. Oh BY, Lee RA, Chung SS, Kim KH. Epidermal growth factor receptor mutaions in colorectal cancer patients. J Korean Soc Coloproctol 2011;27:127-32. 